\title{
Heuristic Projects in Open Learning Environments: Time Phase in Individual and Collective Determinants
}

\author{
Shinyi Lin ${ }^{1 *}$, Chou-Kang Chiu ${ }^{1}$ \\ ${ }^{1}$ National Taichung University of Education, TAIWAN
}

Received 26 February 2018 - Revised 17 August 2018 • Accepted 26 August 2018

\begin{abstract}
Given the inquiry-based nature of research projects, this study aims to investigate how graduate students in business administration majors are being involved in developing, achieving, and completing their master theses. Taking into account of two perspectives including the individual factors and collective environment supported by ICTs, the research purpose is to explore the perception of diverse innovation and to validate its critical determinants while using cloud technologies to collaborate as the research premise. In such an open learning environment (OLE), we adopt a sequential research design to 288 management students of two management colleges in central Taiwan. The research participants were at their three phases, i.e., concept, intermediate, and closure, for their thesis projects. Based on the PLS-SEM analysis, the extent of being in community of practice (COP) was validated statistically as a partial mediator in the two paths: between self-efficacy (SE) and immerse in knowledge ecology (KE), and between self-determination (SD) and KE. Similarly, the perception of individual self-efficacy (SE) identified as another partial mediator between SD and CoP. The differential effect resultant of the time phase on determinants and consequences is also examined. Regardless of the generalized caveats that result from using a non-randomized, regional sample pool, the contribution of this study remains its practical and academic implications in management education and knowledge ecology enhanced in the OLE.
\end{abstract}

Keywords: goal-setting, heuristics, project-based learning, community of practice, self-efficacy, open learning environment, communities of practices

\section{INTRODUCTION AND CONCEPTUAL FRAMEWORK}

In higher education, academic writing and its corresponding research experience have gained attention and discussed persistently not only for master's thesis or doctoral dissertation (Basturkmen, East, \& Bitchener, 2014; Hagström \& Lindberg, 2013; Hunt, 2001; Lindsay, 2015) but also for undergraduates (Stößlein \& Kanet, 2016). In academia, the main purpose of master theses or doctoral dissertations specifically is to provide graduate students with the opportunity to practice conducting and presenting research and to afford them the opportunity to advance an original empirically validated perspective on a topic of their choosing (Thomas \& Brubaker, 2000). When entering graduate school, graduate students begin the process of exploring and initiating their research projects, accordingly overcome challenges for the time. In most cases, students are not assigned academic advisors but instead take steps to get to know their prospective academic advisors. Roberts (2004) suggests that graduate students spend time determining which faculty members are available that might be suitable as an advisor, because the advisor is the leader of the thesis or dissertation committee and is responsible for providing the student with advice and assistance. The steps before the selection of an advisor are selecting a topic and preparing a short written concept paper to assist with the match between student and advisor. Once an advisor is confirmed, the student works with the advisor to refine the intended topic and to plan the research project in a manageable study. To fulfill the degree requirements, students must pass an oral defense of their thesis project after completing all the course work and successfully publishing one or more conference/journal papers as prerequisites. That is, to keep their thesis project on target, graduate students learn to effectively manage an overwhelming load of information and

(C) 2020 by the authors; licensee Modestum Ltd., UK. This article is an open access article distributed under the terms and conditions of the Creative Commons Attribution License (http://creativecommons.org/licenses/by/4.0/). \sin@gm.ntcu.edu.tw (*Correspondence) $\bigotimes$ ckchiu@ntu.edu.tw 


\section{Contribution of this paper to the literature}

- Identifies Individual and collective factors driving innoversity perception of heuristic projects in OLEs.

- Validates phase effect on innoversity perception and its determinants of heuristic projects.

- Provides practical and academic implications of knowledge ecology enhanced in the OLE in management education.

materials. On the other hand, the role of a thesis advisor is identical to that of a coach, a mentor, and even a role model who leads his or her student teams in multiple perspectives. Nonetheless, graduate students are accountable of their research projects with independent and critical thinking skills. In such a domain-specific context, Huang, Jeng, Hsiao, and Tsai (2016) elaborate that the instructional design with a project-based learning (PjBL) in open learning environments (OLEs) incubates vocational undergraduate students with more inspiration and innovation on the learning content accordingly. In graduate education, the thesis projects are the challenging tasks for both students and advisors. Given the perplexing nature of graduate theses, the process involves metacognitive scaffolding of knowing what to know and how to know. Finishing upon the theses takes divergent and convergent thinking to impose, induce, and generate contexts with processing, manipulation, and communication techniques especially. The communication refers to real-time synchronous and time-shifted asynchronous interaction between graduate students and thesis advisor, or among graduate students. The learning and development of graduate thesis best exemplifies the spirit of andragogy that how adults learn.

For thesis and dissertation advisors, Cassuto (2010) brings up five pieces of advice about common issues impeding the writing process. First of all, advisors should make effort to assist graduate students to form peer groups to be involved in a collaborative learning environment. Secondly, keeping in mind of what students are interested in, advisors should consistently monitor whether the students still keep up with the thesis proposal or the research topic in case that the students might be off the research track or topic that no longer stirs their passion. Thirdly, advisors should attempt to help students write less stressfully and avoid relying on highly structured composition chapter by chapter from the preliminary stage. Fourthly, advisors could remind students that the spirit of theses or dissertations is the process of learning and advising, not just a polished display of learning. Lastly, advisors should closely monitor students' writing progress to prevent them from academic procrastination. To lead student teams, thesis advisors assume the responsibilities of managing the path and pace by supervising coursework planning, advising thesis projects, and even consulting on career planning after graduation. Both thesis advisors and graduate students could benefit from mutual and effective communication, which can be promoted by information and communication technologies (ICTs) with strategic knowledge management.

Having the premise that thesis project requires deductive and inductive reasoning skills, the graduate students use cloud technologies for effective communication and collaborative learning for their thesis projects. This study takes account of self-determination theory and goal-setting theory to justify individual factors, and community of practice $(\mathrm{CoP})$ notion to extend collective factors as related to the ICT-supported open environment. This study aims to respond to the two research questions.

1. What individual and collective factors drive students' innoversity perception of heuristic projects in such an OLE?

2. In the OLE, what are the differential effects of writing phases on the heuristic projects and its associated determinants?

\section{RESEARCH MODEL AND HYPOTHESES}

\section{Innoversity Perception}

Groups of people with common interests form communities of practices (CoPs) to meet and share insight on developing comparably effective solutions to challenges (Wenger, McDermott, \& Snyder, 2002), and such type of community is called communities of practices (CoPs). On the basis of the premise that innovation can be promoted by CoPs, Hildreth and Kimble (2004) introduce the term innoversity as the notion of the role of diversity in fostering innovation. To cultivate learning and innovation in CoPs, Hildreth and Kimble (2004) encourage the timing and circumstances of innovative practice diversity and further identify five drivers of innovation, which they call innoversity drivers because each of them establishes diversity as an essential source of innovation in and among CoPs ( $\mathrm{p}$. 85). The five drivers are (1) absorptive capacity, (2) requisite variety, (3) network variety, (4) creative destruction, and (5) problem solving. Because graduate students work on a thesis for nearly a year, thesis advisors tend to instruct their advisees in a group and expect that senior students act as mentors to junior students. Student peers also tend to share information and exchange ideas. In such collaboration, the study assumes that students tend to either be motivated by peers from different backgrounds or be inspired by their advisors to develop their own sense 
of innovation from the time of thesis writing. Therefore, we conceptually define absorptive capacity and requisite variety as innoversity perception (IP), which is the major element of research projects.

\section{CoPs and Knowledge Ecology (KE)}

People engaged in CoPs participate in different paths and at different paces (Kimble, Hildreth, \& Bourdon, 2008). As major sources of influence in an organization, CoPs could enhance organizational strategy and innovation, develop more effective practice, support and teach members, and instill a philosophy of learning and sharing in a larger business community (Debowski, 2007). Considering the CoP as a whole, members focus on learning through practice to improve their own practice (Kimble et al., 2008). In CoPs, innovation, collaboration, and the sharing of good practice is highly encouraged (Debowski, 2007). Specifically to support the creation of CoPs, the necessary prerequisites are commitment, generosity, and the development of a collectivist mentality (Bishop \& International, 2002).

Derived from the essence of CoPs, Chatti (2012) developed the concept of knowledge ecology (KE), which refers to a social entity with no explicit boundaries or membership criteria. Specifically, KE involves an emergent network in which people are bound, but not as tightly as in a CoP. That is, KE is driven more by independence and autonomy than authorized membership, mutual engagement, and belonging to a specific community as CoPs are. Rather than being forced to interact intensely with other members of a CoP, people can rely on their personal knowledge network in KE (Chatti, 2012). Given the context of small and medium enterprise e-learning, Lin, Hung, and Lee (2015) delineate how self-efficacy mediates full between social and cognitive presence. Self-efficacious belief of one individual is highly related to their being in online community. Likewise, Shea and Bidjerano (2008) provide practical insights of how asynchronous ICT-mediate communication aspires learning persistence and cognitive presence in high education. Considering that thesis writing typically requires higher order cognitive activities, advisor mentors or student peers tend to generate mutual and meaningful dialogue. Given the premise that thesis advisor is the supporting role to guide and monitor students' thesis writing, being in the ICTs-enhanced environment prompts those students to share information and, most importantly, the lesson learned with each other. Therefore to reiterate, we define the concept of communities of practices (CoPs) as the extent that one individual perceives oneself being involved in an online community for the same interest and objective. On the other hand, we delineate knowledge ecology (KE) as not just being in an online community as in CoPs, but with one's sense of independence and autonomy for the learning. That is, whether learners reflect such ICT-enhanced cloud communities leans either CoPs or KE resulting in a stronger perception of innoversity anticipates for the empirical validation.

\section{Goal Setting}

Goal-setting theory (GST) was firstly discussed by Locke (1968), later proposed by Locke, Cartledge, and Knerr (1970), and persistently evolved by Locke and Latham (1990), Latham and Locke (1991), Locke and Latham (2002), Locke and Latham (2006), and Locke and Latham (2015). The notion of goal setting (GS) is generally stressed collaboratively, negotiating goals and action plans (Bodenheimer \& Handley, 2009). As one of the most empirically validated theories in the field of in-service training and workplace psychology, GST has also been highly influential in effecting popular management practice (Catania, 2014; Landers, Bauer, \& Callan, 2017). In a macro view, GSTrelated research has also been extended from individuals at the group level to the level of the organization as a whole (Locke \& Latham, 2006). Berson, Halevy, Shamir, and Erez (2015) elaborate that setting goals tends to be more focused and increases the level of individual commitment and effort to accomplish specific goals which include the group commitment and effort devoted to accomplish group-based goals. In their empirical study of sales control systems on job performance, Fang, Evans, and Zou (2005) operationally define goal difficulty, goal specificity, and goal participation as the three basic characteristics of GST. Locke and Latham (1990) stress that the goal characteristics have the potential to influence the likelihood of successful attainment of the goal; that is, the more specific the goal is, the greater is the likelihood of its attainment, whereas the more vague or ambiguous the goal is, the less likely it is to be attained.

Locke and Latham (2002) explain that people with high goals devote greater effort than do those with low goals. Because GS relates to the perception of self-efficacy (SE), individuals with high self-efficacy set higher goals than do those with lower self-efficacy when the GS depends on the individual level.

\section{Self-determination}

Self-determination theory (SDT), a theory of motivation, addresses people's initiation of an action (Grolnick, 2015). Ryan and Deci (2000) elaborate motivation as defined in SDT and differentiate intrinsic motivation from extrinsic motivation according to the reasons or goals that engender an action. That is, intrinsic motivation refers to executing an action because it is inherently interesting or enjoyable, and extrinsic motivation refers to executing 
something because it leads to a separable outcome. Regarding online learning, Chen and Jang (2010) propose that SDT proffers humans three intuitive needs: autonomy (a sense of control), competency (being proficient with tasks and/or activities), and relatedness (feeling connected with others). Intrinsic motivation tends to incubate a higher quality of learning and creativity; therefore, it is particularly crucial to detail the factors and forces that engender rather than undermine it (Ryan \& Deci, 2000). Along the line, Zhao, Lu, Wang, and Huang (2011) adopt the three aforementioned elements, i.e., perceived autonomy, competence, and perceived relatedness, to explore internet use of high school students.

\section{Time Issue}

As the time issue directly impacts the what, how, and why elements of a theory building, George and Jones (2000) propose that although time can be conceptualized narrowly as a boundary condition, it can and should be given much greater importance. Sonnentag (2012) asserts that time should be incorporated into theory development and refinement through four alternative tactics: (1) studying time-related constructs, (2) investigating time-sensitive processes, (3) specifying adequate time lags, and (4) taking the temporal context into account. Similarly, concerning the issue of time perspective, Fried and Slowik (2004) discuss how the incorporation of time can enhance the understanding of the major components of GST, because of the current rapid changes in work environments involving unprecedented growth in technology, innovation, and changes in work structure.

As noted, considering the thesis project from conception to final closure, three phases are identified as breaking points: (1) concept phase, (2) intermediate phase, and (3) closure phase. During the concept phase from idea development to authorization, students must manage the issues of source of guidance (i.e., academic advisors, supervising committees, and fellow graduate students), literature search, definition of research topic, and development of theories. In the intermediate phase from authorization to implementation, students engage majorly in data collection and result interpretation. In the closure phase from implementation to closure, they complete the thesis project and prepare the manuscript for publication, if required. In the context of thesis writing in graduate schools of management education, the purpose of this study is to understand the developmental progress of thesis writing from the perspectives of student advisees and to determine the antecedents of innoversity perception of the intended participants of interest.

Based on the multiple theories, i.e., self-determination theory, goal-setting theory, self-efficacy theory, and community of practice, the research model framing this study is illustrated in Figure 1. The model depicts both individual determinants and collective determinants as direct and/or indirect antecedents to innoversity perception. In addition to the one-on-one causal hypotheses as displayed in the model, this also validates differential effect of the three phases on all of the determinants as H14. A series of mediating effect would be supplementary depending on the one-on-one causal tests. 


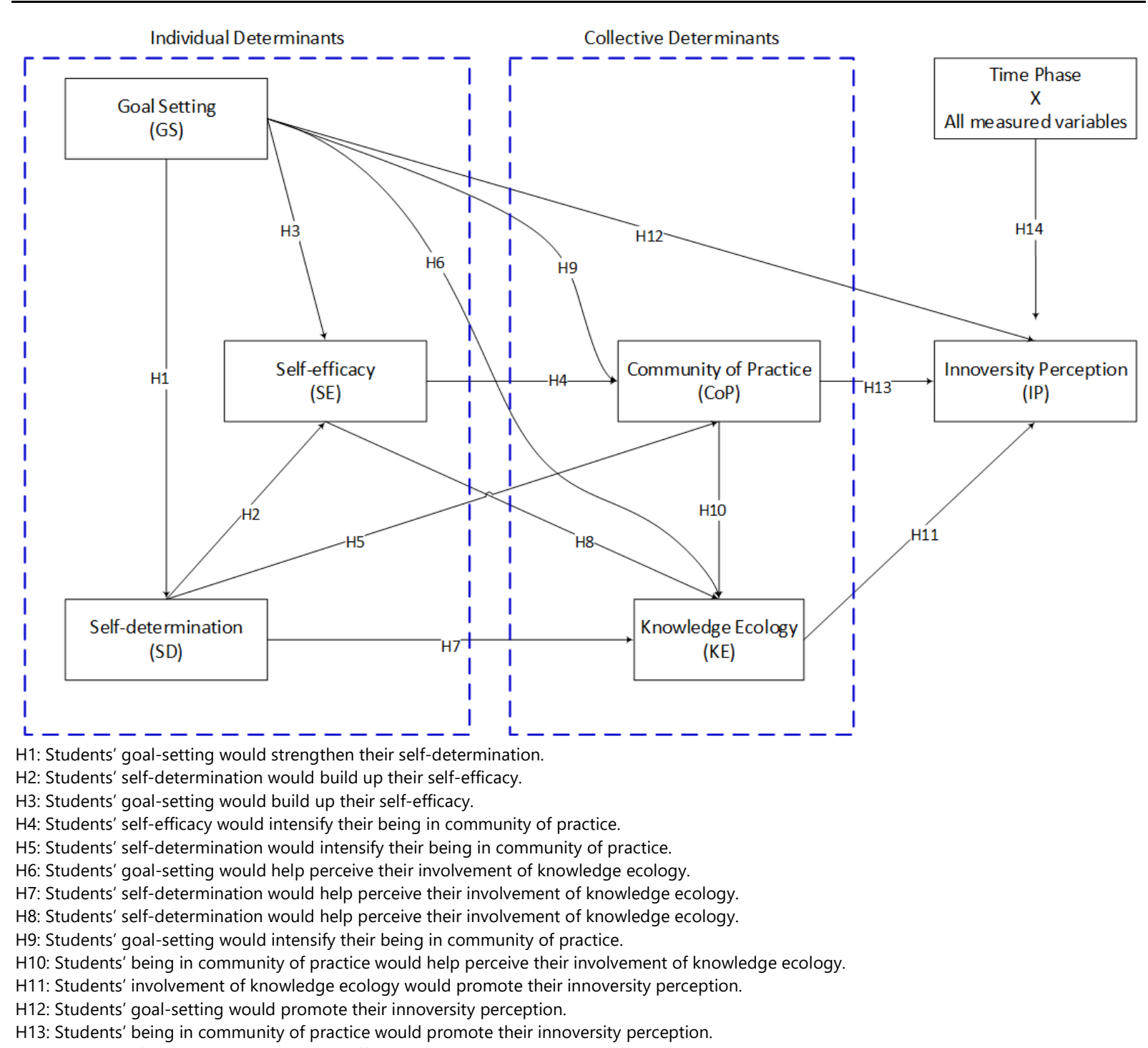

H14: Students of the three phases present differently on innoversity perception and its associated determinants.

Figure 1. Research conceptual framework

\section{METHODS}

During the developmental progress of thesis writing from the perspective of student advisees, the research purpose is to understand the determinants of the innoversity perception among graduate students toward their thesis writing, and the differential effects of writing phases while using cloud technologies to assist the communication and knowledge management. In general, a cross-sectional design mainly enables researchers to collect data in a short period; however, the ease of data collection tends to cause threats to validity. To control for threats to internal validity and to effectively conduct the investigation process, this study employed a sequential design integrating both cross-sectional and longitudinal designs during the midterm week of a spring semester.

Participants were graduate students majoring in management education at both national and private universities in Central Taiwan. Out of 435 graduate students volunteered to participate in the study, the 288 graduate students with $66 \%$ valid return were screened by using cloud technologies as a major channel to communicate and discuss with their thesis advisor, and exchange information with the student peers also supervised by the same advisor. Of the 288 valid participants, $25 \%(n=72)$ were in the concept phase, $36.8 \%(n=$ $106)$ in the intermediate phase, and $38.2 \%(n=110)$ in the closure phase. $42 \%(n=120)$ of the participants were males, and 58\% ( $n=168)$ were females. Regarding the degree being pursued, $20 \%(n=58)$ of the participants were doctoral students and $80 \%(n=230)$ were master's students. Considering the time issues of thesis writing, this study divided the writing process into the three phases described in Table 1. Concerning demographics, no significant difference was observed among the three phases in terms of gender representation $\left(\chi^{2}(2)=2.099, p=.35\right)$. 
Table 1. Three phases of thesis writing defined for the study

\begin{tabular}{|c|c|c|}
\hline $\begin{array}{l}\text { Concept phase } \\
25 \%(n=72)\end{array}$ & $\begin{array}{l}\text { Intermediate phase } \\
36.8 \%(n=106)\end{array}$ & $\begin{array}{l}\text { Closure phase } \\
38.2 \%(n=110)\end{array}$ \\
\hline (From idea to authorization) & (From authorization to implementation) & (From implementation to closure) \\
\hline$\sqrt{ } \quad$ Invite a thesis advisor & Collect empirical data & Wrap up the final version \\
\hline Confirm a research topic & Analyze collected data & Prepare the oral defense \\
\hline Review the literature & Interpret results & Prepare for publication \\
\hline$\checkmark \quad$ Develop research model & & \\
\hline
\end{tabular}

\section{RESULTS}

On the basis of the literature, the operational definitions of the scale items were stated accordingly to ensure the contextual consistency, and complete scale items were presented in Appendix. In the presence of content-related and criterion-related validity, the confirmation of convergent and discriminant validity remains crucial as to the overall research validity (Arthur, Woehr, \& Maldegen, 2000). The participants rated their perception on an 8-point Likert scale, ranging from 1 (strongly disagree) to 8 (strongly agree), in addition to the demographic and background information.

\section{Measurement Model}

Assessing construct measures of reflective measurement models includes for the indicator reliability of internal consistency and construct validity, i.e., convergent validity, discriminant validity. To ensure scale reliability, Bagozzi and Yi (1988) recommend that instead of the Cronbach's alpha value, a composite reliability (CR) value of .70 (threshold) be considered acceptable. CR values ranging from .60 to .70 in exploratory research and values from .70 to .90 at more advanced stages of research are considered satisfactory (Joe F Hair, Ringle, \& Sarstedt, 2011). In this study, all CR values in the measurement models ranged from .882 of GS to .959 of IP, which validate the measurement scales.

The construct validity can be examined through convergent validity and discriminant validity. Convergent validity relates to the degree to which multiple methods of measuring a variable provide the same results ( $\mathrm{O}^{\prime}$ LearyKelly \& Vokurka, 1998). Additionally, average variance extracted (AVE), representing the proportion of the average variance between constructs and indicator variables, must be greater than .50 to indicate a sufficient degree of convergent validity (Joe F Hair et al., 2011). All CR and AVE of the measures indicate favorable convergent validity (Table 2). That is, a valid measure refers to that the variance in the measure should reflect only the variance attributable to its intended latent variable instead of to other latent variables (O'Leary-Kelly \& Vokurka, 1998). On the other hand, the square root of the AVE should be greater than the correlations of variables to prove discriminant validity (Fornell \& Larcker, 1981). Each construct had a greater square root of the AVE than its correlations with other constructs, indicating that the values of diagonal elements are greater than those of off-diagonal elements, thus demonstrating the discriminant validity of our measurement items (Chin, 1998; Fornell \& Larcker, 1981; Hulland, 1999). In addition to the Fornell-Larcker criterion and (partial) cross loadings by Fornell and Larcker (1981), the heterotrait-monotrait ratio of correlations is a new criterion for assessing discriminant validity in variance-based structural equation modeling (Henseler, Ringle, \& Sarstedt, 2015). For assessing multicollinearity, the variance inflation factor (VIF) value of each indicator should be lower than 5.00 (Joe F Hair et al., 2011). As shown in Table 3, the outer VIF values of the indicators varied between 1.502 and 4.701, complying with the suggested threshold of less than 5.00 . 
EURASIA J Math Sci and Tech Ed

Table 2. Composite reliability and construct validity by Fornell-Larcker Criterion

\begin{tabular}{cccccccccc}
\hline & CR & AVE & Mean & CoP & GS & IP & KE & SD & SE \\
\hline CoP & .959 & .887 & 6.405 & $\underline{.942}$ & & & & & \\
\hline GS & .882 & .714 & 6.928 & .488 & $\mathbf{. 8 4 5}$ & & & \\
\hline IP & .905 & .658 & 6.646 & .737 & .610 & $\mathbf{. 8 1 1}$ & & \\
\hline KE & .914 & .781 & 6.345 & .745 & .506 & .723 & $\underline{.883}$ & & \\
\hline SD & .905 & .761 & 6.523 & .621 & .706 & .758 & .682 &. $\mathbf{8 7 3}$ & \\
\hline SE & .900 & .751 & 6.093 & .686 & .513 & .782 & .752 & .729 & $\underline{.867}$ \\
\hline
\end{tabular}

Note:

1. $\mathrm{CR}=$ composite reliability; $\mathrm{AVE}=$ average variance extract

2. $\mathrm{GS}=$ goal setting; $\mathrm{SE}=$ self-efficacy; $\mathrm{CoP}=$ community of practice; $\mathrm{KE}=$ knowledge ecology; $\mathrm{SD}=$ self-determination; $\mathrm{IP}=$ innoversity perception.

3. Off-diagonal elements represent correlations between the constructs. Diagonal elements represent the square root of the shared variance between the constructs and their measures. The square root of the shared variance across items measuring a construct was higher than the correlations across constructs, supporting discriminant validity across constructs.

Table 3. Outer loadings and collinearity statistics (VIF)

\begin{tabular}{|c|c|c|c|c|c|c|c|}
\hline & VIF & IP & CoP & GS & KE & SD & SE \\
\hline IP1 & 1.506 & .688 & & & & & \\
\hline IP2 & 2.281 & .817 & & & & & \\
\hline IP3 & 1.754 & .796 & & & & & \\
\hline IP4 & 2.530 & .857 & & & & & \\
\hline IP5 & 3.214 & .885 & & & & & \\
\hline CoP1 & 3.526 & & .929 & & & & \\
\hline CoP2 & 4.701 & & .950 & & & & \\
\hline CoP3 & 4.329 & & .946 & & & & \\
\hline GS1 & 1.502 & & & .780 & & & \\
\hline GS2 & 1.911 & & & .853 & & & \\
\hline GS3 & 2.294 & & & .898 & & & \\
\hline KE1 & 2.082 & & & & .863 & & \\
\hline KE2 & 2.735 & & & & .918 & & \\
\hline KE3 & 2.076 & & & & .868 & & \\
\hline SD1 & 1.610 & & & & & .886 & \\
\hline SD2 & 2.545 & & & & & .903 & \\
\hline SD3 & 2.672 & & & & & .827 & \\
\hline SE1 & 1.568 & & & & & & .796 \\
\hline SE2 & 2.509 & & & & & & .900 \\
\hline SE3 & 2.394 & & & & & & .899 \\
\hline
\end{tabular}

Note: GS = goal setting; SE = self-efficacy; CoP = community of practice; KE = knowledge ecology; SD = self-determination; IP = innoversity perception

\section{Structural Model}

The examination of the structural model involved estimating the path coefficients and the $R^{2}$ values. The path coefficients represent the magnitude of the expected change in the observed variables, and the $R^{2}$ values indicate the amount of variance in dependent variables explained by their antecedents (Vinzi, 2010). The most commonly used measure to evaluate the structural model is the $R^{2}$ value, the coefficient of determination (J. F. Hair, 2013). The $R^{2}$ values and path coefficients demonstrate the extent to which the data validate the research model. Joe F Hair et al. (2011) suggest that endogenous latent variables in the structural model can be described as substantial, moderate, or weak, according to the $R^{2}$ values of .75 , .50, or .25, respectively. As in Figure 2, the results of the structural model present the explained variance, path coefficients, and associated $t$ values of the hypothetical paths discussed in the study. The primary advantage of bootstrapping is to enable researchers to assess the stability of parameter estimates, and to accurately report the values (Byrne, 2009). In the analysis, the variance of SD $\left(R^{2}=.498\right)$ was explained by that of GS $(\beta=.706, p<.001)$; the variance of $\mathrm{SE}\left(R^{2}=.532\right)$ was explained by that of SD $(\beta=.732$, $p<.001)$, but not by GS $(\beta=-.003, p>.05)$. The variance of CoP $\left(R^{2}=.507\right)$ was explained by those of SE $(\beta=.497$, $p<.001)$ and SD $(\beta=.188, p<.01)$, but not by GS $(\beta=.101, p>.05)$. In addition, the variance of $\operatorname{KE}\left(R^{2}=.778\right)$ was explained by those of $\mathrm{CoP}(\beta=.592, p<.001)$, SD $(\beta=.137, p<.05)$, and SE $(\beta=.249, p<.001)$, but not by GS $(\beta=-$ $.008, p>.05)$. Overall, the five antecedents explained $73.0 \%$ of the variance in IP. The $R^{2}$ values ranged from .507 to .730 , which can be considered moderate. 


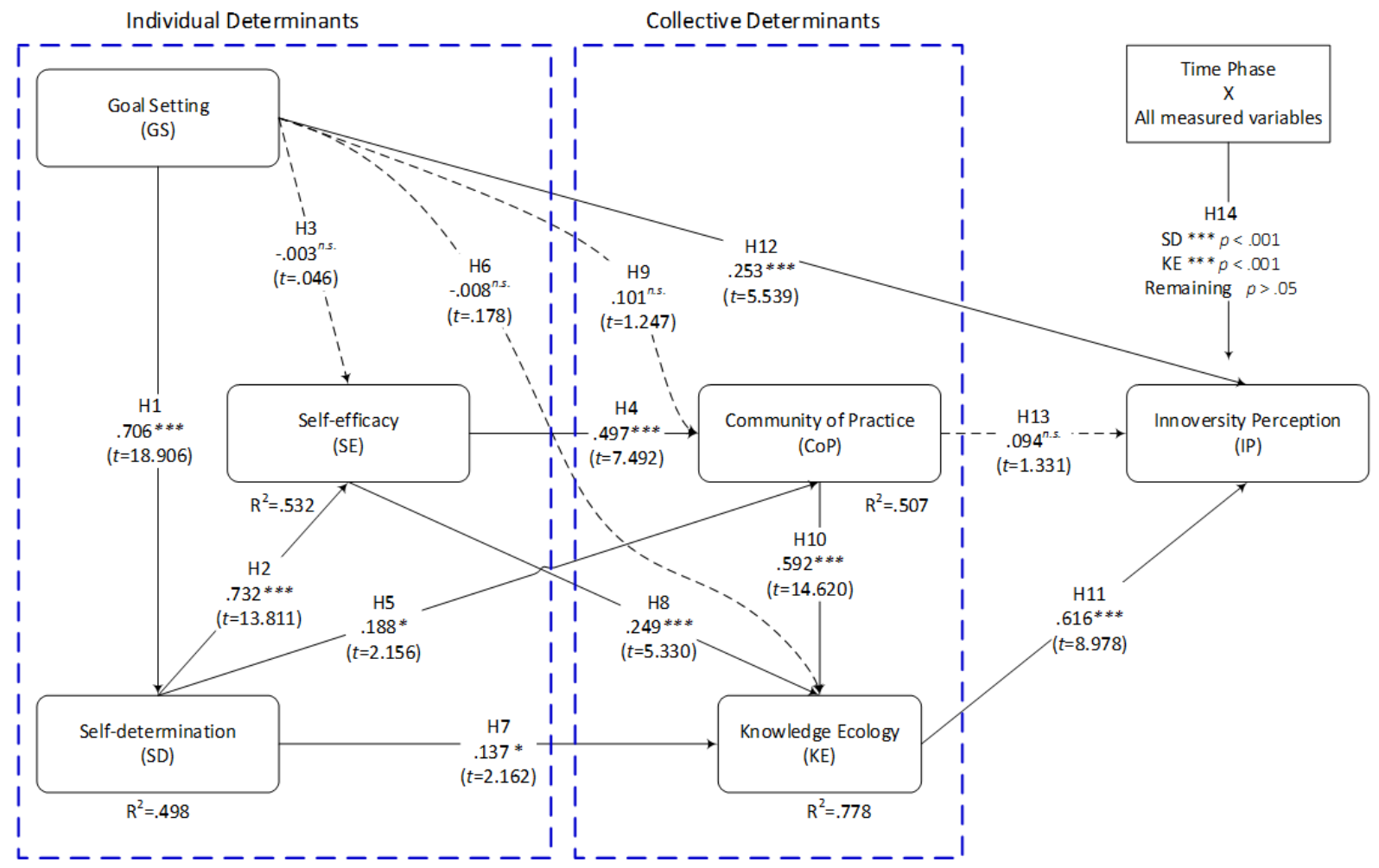

Figure 2. Structural model of the study

In addition, the effect size $f^{2}$ of GS on the endogenous latent variable IP is .173, the medium effect. The effect size $f^{2}$ of KE on the endogenous latent variable IP is .385, the large effect. The effect size $f^{2}$ of CoP on the endogenous latent variable KE is .778, also the large effect. Similarly, the effect size $f^{2}$ of SD on the endogenous latent variable $\mathrm{SE}$ is .574, the large effect. Guidelines for assessing $f^{2}$ are that values of $0.02,0.15$, and 0.35 , representing small, medium, and large effects of the exogenous latent variable respectively (Cohen, 1988).

Henseler et al. (2014) introduce the SRMR as a goodness-of-fit (GoF) index measure for partial least squares structural equation modeling. The GoF index can be useful for assessing how sufficiently a partial least squares (PLS) path model can explain different sets of data (Henseler \& Sarstedt, 2013). When the PLS algorithm is run, the results report the SRMR criterion in two outcomes: (1) for composite models, and (2) for common factor models. In general, when all the measurement models are reflective, the SRMR common factor model is the relevant model fit assessment criterion. In a more conservative view, a value between .08 and .10 is considered a good fit. For the SRMR results, this study determined .069 for composite models and .077 for common factor models, which seem a good fit accordingly.

\section{Phase Effect on Innoversity Perception and its Determinants}

A between-subjects multivariate analysis of variance was conducted on innoversity perception and its determinants, serving as the dependent variable. The three phases of thesis writing (concept, intermediate, and closure) served as the independent variables. Through the use of Wilks' lambda $(\lambda)$, a differential effect of the phases was found in SD $\left(\lambda=.792, F(2,285)=4.923, p<.001\right.$, partial $\left.\eta^{2}=.997\right)$ and $\operatorname{KE}(\lambda=.866, F(12,282)=3.37, p$ $<.001$, partial $\left.\eta^{2}=.997\right)$. For the main effect of the phases, Tukey's honest significant difference post hoc tests suggested that participants who were in the closure phase $(M=6.745, S E=.107)$ demonstrated higher SD than did those who were in the concept phase $(M=6.350, S E=.132)$. No statistically significant phase effects were observed for SD between the concept and intermediate phases $(p>.05)$, as shown in Figure 3. 


\section{Phase $x$ Constructs}

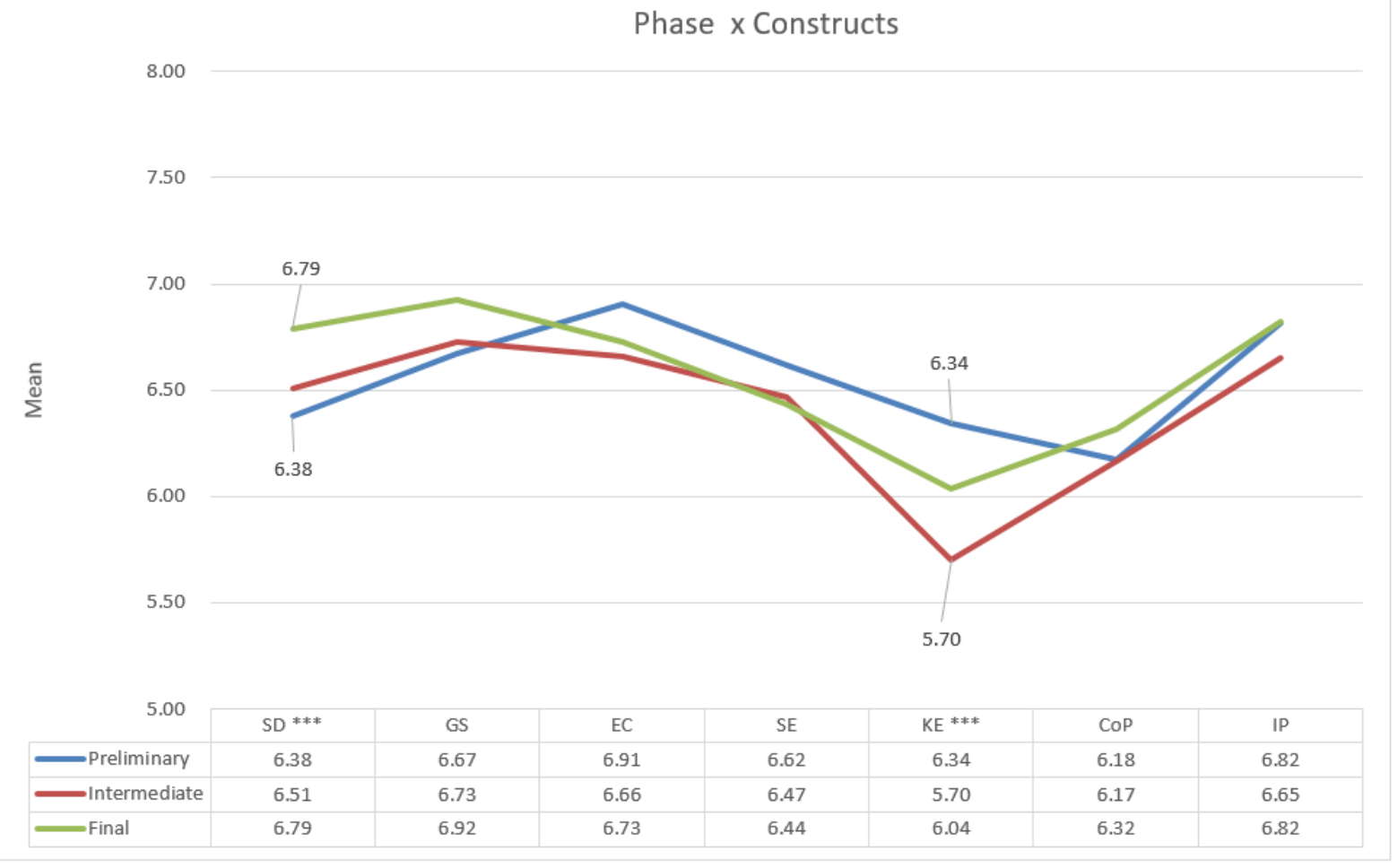

Figure 3. Phase effect on the measured constructs

Two-tailed probability: ${ }^{* \star *} p<.001$

Table 4. Mediating effect of CoP and SE

\begin{tabular}{|c|c|c|c|c|c|c|c|c|}
\hline Constructs & Mediator & $\begin{array}{c}\text { Subordinate } \\
\text { Paths }\end{array}$ & $\begin{array}{c}\text { Path } \\
\text { coefficient }(\beta)\end{array}$ & t-test & $\begin{array}{c}\text { Standard } \\
\text { error } \\
\text { (STEER) }\end{array}$ & $\begin{array}{c}\text { Sobel's } \\
\text { test (z } \\
\text { value) }\end{array}$ & VAF & $\begin{array}{c}\text { Mediating } \\
\text { effect }\end{array}$ \\
\hline $\mathrm{SE} \rightarrow \mathrm{COP} \rightarrow \mathrm{KE}$ & CoP & $\begin{array}{l}\mathrm{SE} \rightarrow \mathrm{COP} \\
\mathrm{COP} \rightarrow \mathrm{KE}\end{array}$ & $\begin{array}{l}.497 \\
.592\end{array}$ & $\begin{array}{c}7.492 \\
14.620\end{array}$ & $\begin{array}{l}.070 \\
.040 \\
\end{array}$ & 10.272 *** & $54.14 \%$ & Partial \\
\hline $\mathrm{SD} \rightarrow \mathrm{CoP} \rightarrow \mathrm{KE}$ & $\mathrm{CoP}$ & $\begin{array}{l}\mathrm{SD} \rightarrow \mathrm{CoP} \\
\mathrm{CoP} \rightarrow \mathrm{KE}\end{array}$ & $\begin{array}{l}.188 \\
.592\end{array}$ & $\begin{array}{c}2.156 \\
14.620\end{array}$ & $\begin{array}{l}.088 \\
.040\end{array}$ & 2.445 * & $44.76 \%$ & Partial \\
\hline $\mathrm{SD} \rightarrow \mathrm{SE} \rightarrow \mathrm{CoP}$ & SE & $\begin{array}{l}\mathrm{SD} \rightarrow \mathrm{SE} \\
\mathrm{SE} \rightarrow \mathrm{CoP}\end{array}$ & $\begin{array}{l}.732 \\
.497 \\
\end{array}$ & $\begin{array}{c}13.811 \\
7.492 \\
\end{array}$ & $\begin{array}{l}.060 \\
.070 \\
\end{array}$ & $9.705^{* \star *}$ & $65.94 \%$ & Partial \\
\hline
\end{tabular}

Note:

1. $\mathrm{SE}=$ self-efficacy; $\mathrm{COP}=$ community of practice; $\mathrm{KE}=$ knowledge ecology; $\mathrm{SD}=$ self-determination; $\mathrm{IP}=$ innoversity perception.

2. $\mathrm{VAF}=$ Variance of $\mathrm{VAF}<20 \%=$ none mediation. ; $20 \% \leqq \mathrm{VAF} \leqq 80 \%=$ partial mediation

3. Two-tailed probability: ${ }^{*} p<.05 ;{ }^{* * *} p<.001$

\section{Mediating Effects of CoP and SE}

When considering estimated cause-effect relationship results might not the real case due to a systematic influence, i.e., a mediator, J. F. Hair (2013) suggest a mediator analysis to understand possible phenomenon between independent variables and dependent variables. As commonly known and use approach to analyze the mediating effect of interest, the Sobel test by Sobel (1982) adopts an absolute Z-value of the paths greater than the threshold value of 1.96, suggesting the presence of a mediating effect. Furthermore, Joseph F Hair, Hult, Ringle, and Sarstedt (2014) propose that to test for mediating effect in PLS-SEM, it is better to use the variance accounted for (VAF) than the Sobel test. Determining the size of the indirect effect as in the total effect, the VAF applies bootstrapping to assess the path coefficients' significance and fine tune the effect power compared to the Sobel test. In the case, if the VAF is less than $20 \%$, we can conclude that no mediation occurs. On the other hand, when the VAF is larger than $80 \%$, we assume a full mediation. That is, partial mediation is assumed when the VAF is between $20 \%$ and $80 \%$ (J. F. Hair, 2013). As in Table 4, CoP was validated statistically as a partial mediator in the two paths: between SE and $\mathrm{KE}$, and between SD and KE. Similarly, SE identified as another partial mediator between SD and CoP. 
Table 5. Data of the IPMA Path Model on innoversity perception (IP)

\begin{tabular}{cccc}
\hline & & Importance (Total Effect) & Performance (Index Values) \\
\hline \multirow{2}{*}{ Collective determinant } & CoP & .46 & 78 \\
\cline { 2 - 4 } Individual determinant & KE & .63 & 74 \\
\cline { 2 - 4 } & GS & .62 & 80 \\
\cline { 2 - 4 } & SD & .45 & 78 \\
\cline { 2 - 4 } & SE & .36 & 76 \\
\hline
\end{tabular}

\section{Importance-Performance Map}

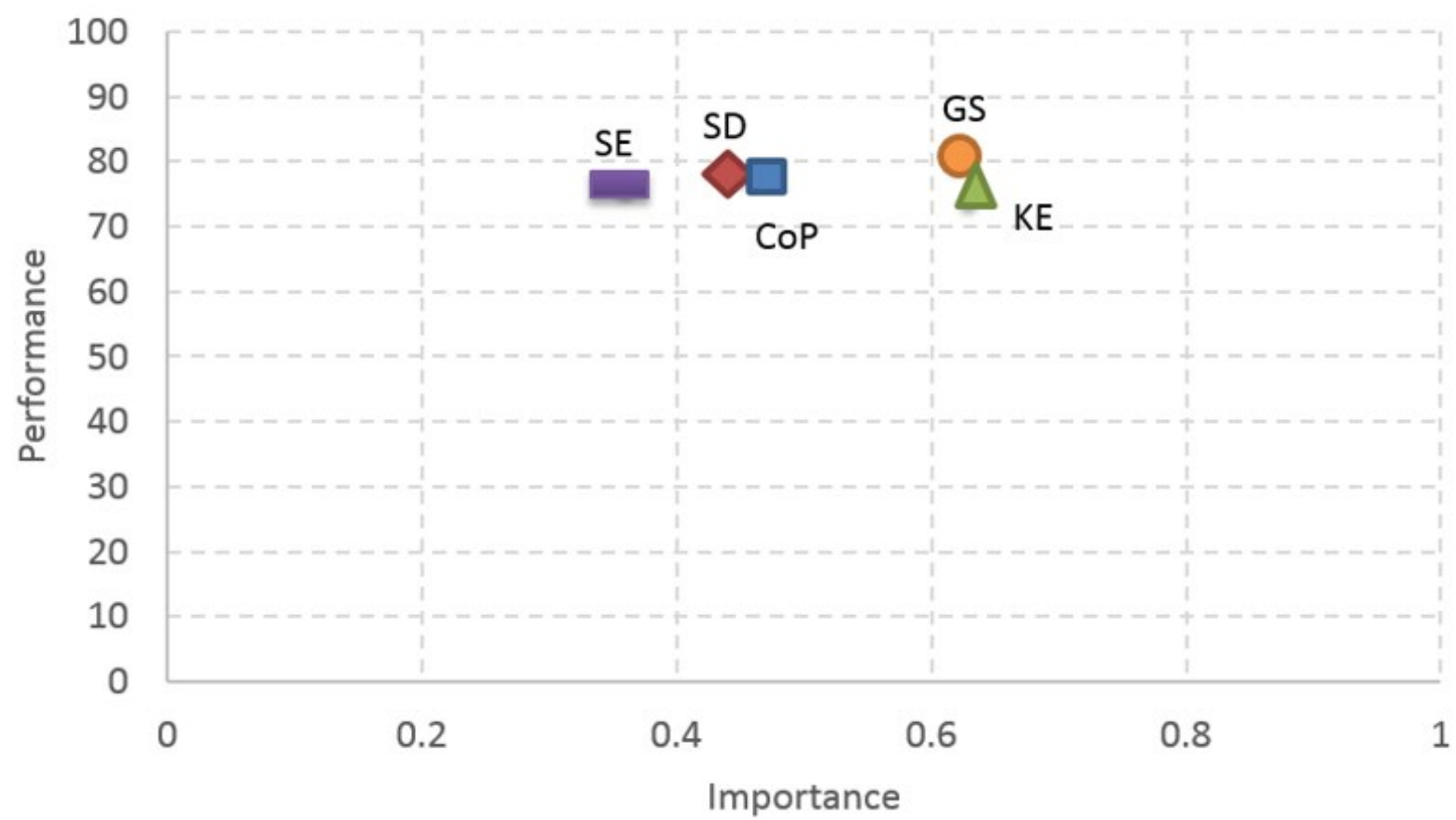

Figure 4. IPMA Results of innoversity perception (IP) as target construct

\section{Importance-Performance Matrix Analysis (IPMA)}

According to J. F. Hair (2013), a basic PLS-SEM analysis identifies the relative importance of constructs in the structural model by extracting estimations of the direct, indirect, and total relationships. Extending the results of PLS-SEM, the importance-performance matrix analysis (IPMA) takes the performance of each construct into account, and contrasts the structural model total effects (importance) and the average values of the latent variable scores (performance) to highlight critical determinants for the improvement of management practices (J. F. Hair, 2013). The IPMA requires obtaining the total effects of the relationships of all the other constructs (i.e., GS, SD, SE, $\mathrm{CoP}$, and $\mathrm{KE}$ ) on the target construct of INN to indicate their importance. The total effect of a relationship between two constructs is the sum of all the direct and indirect effects in the structural model; that is, the total effect equals to direct effect and indirect effect. The data used for the IMPA of innoversity perception (IP) as latent variable is presented in Table 5 and illustrated in Figure 4 for a graphical representation of results. In the perspective of individual determinants, GS tends to be the most critical in both importance and performance dimension while SE is the least critical pertaining to IP. For the collective determinants, CoP, on the other hand, has little relevance because it is of low importance even though it has slightly high performance compared to KE. Overall, CoP and SD are of similar importance and considerable high performance.

\section{DISCUSSION AND IMPLICATIONS}

The aim of the current research is to contribute to the literature on how student advisees perceive their own innovativeness during the yearlong thesis writing process. Through the lens of an integrated theoretical framework of GST and SDT, we reveal the preliminary findings. As Hildreth and Kimble (2004) state that innoversity perception of individuals in a group tend to be influenced by their sense of CoPs, however our result does not 
support their finding. We find that those students working on their thesis writing tend to work independently with ill-defined structure and schedule disregarding the type of communication channel. Such a situational nuance ascertains that graduate students take the full ownership and accountability themselves nonetheless they share information or exchange idea with each other. That is, the concept of KE takes greater scope as compared to the definition of CoPs. Likewise, Chatti (2012) concluded that people tend to interact frequently and compactly with the other members within a CoP while in the perspective of KE, they focus and stress more on building their personal knowledge network and management. Of the individual determinants, one with affirmative goal setting tends to have greater innoversity perception regardless of collective settings. The sense of community, either community of practice or knowledge ecology, is strategic media to individual innovation.

Those who with high self-efficacious beliefs tend to have a greater sense of CoP as well as greater involvement in the cultivation of KE. Involvement in KE was identified to be the critical path leading to the cultivation of a greater sense of innoversity. Compared with a $\mathrm{CoP}$, the sense of being involved in $\mathrm{KE}$ emphasizes individual autonomy and independence toward the knowledge body and is not as cohesive as a CoP, which necessitates tighter interactions among its members. Thesis writing inherently emphasizes independent work, especially during the intermediate and closure phases. We identified students' perception of being involved in KE to be highest in the concept phase, stretching from conceptualization of the thesis topic to receiving authorization to pursue that topic. During this phase, student advisees ought to closely communicate and discuss with their thesis advisors and collaborate with their student peers in exchanging information and skills in research (e.g., database and bibliographic management tool use). The concept phase seems to emphasize collaboration with others, but students obtain deeper knowledge through authentic dialogue with their advisors. When entering the intermediate phase, students begin data collection. The students mostly interact with their peers on statistical analysis and result interpretation, but this is just a technical, step-by-step procedure and does not build their knowledge scaffolding. Similarly, the students in the closure phase prepare oral defenses and finalize the thesis writing, and they tend to follow a structured process. That students being led into the thesis writing community is not tantamount to a guarantee of innoversity perception, which requires highly motivated and self-directed attitudes toward KE. That is, to achieve higher innoversity through a thesis project, students' mutual engagement and belonging to a specific CoP would not suffice; an exercise in self-regulation and independence is still required.

Students in the closure phase have higher SD compared with those in the concept phase; the more specific the goals are, the more determined the students become. Those who are close to their oral defense develop increased confidence and devote more time to in-depth thinking and self-regulation. The student advisees' effort continuance may be a critical factor from the outset as they make decisions to accomplish the theses as scheduled until they cultivate a sense of innoversity during the writing process; that is, students' perception of being involved in the community and, perhaps, effort continuance stimulate their cultivation of a sense of innoversity toward their thesis project.

For the viewpoint of learning and development, graduate thesis is a typical example of inquiry-based learning in which learner autonomy, metacognitive scaffolding, and ICTs literacy are critical to the completion. Different from the semester courses in more directed learning environments, thesis projects are situated in open-ended learning environments (OLE). Graduate students have gone through heuristic experience of linking cognition of the learned and research context to discern the essence of thesis projects. The results of this study are not only of theoretical importance but also of major practical implications for thesis advising and development from the perspectives of graduate students and faculty advisors. The practical implication of this study contributes validation of an integrated theoretical model of the interest and exploration of the potential application of CoPs as a form of knowledge management network in different subject domains.

\section{ACKNOWLEDGEMENT}

The author would like to thank the Ministry of Science and Technology, Taiwan, for financially supporting this research under Project No. of MOST 102-2511-S-142 -013.

\section{REFERENCES}

Arthur, W., Woehr, D. J., \& Maldegen, R. (2000). Convergent and discriminant validity of assessment center dimensions: A conceptual and empirical reexamination of the assessment center construct-related validity paradox. Journal of Management, 26(4), 813-835. https:/ / doi.org/10.1177/014920630002600410

Bagozzi, R. P., \& Yi, Y. (1988). On the evaluation of structural equation models. Journal of the Academy of Marketing Science, 16(1), 74-94. https:/ / doi.org/10.1007/BF02723327 
Basturkmen, H., East, M., \& Bitchener, J. (2014). Supervisors' on-script feedback comments on drafts of dissertations: socialising students into the academic discourse community. Teaching in Higher Education, 19(4), 432-445. https:/ / doi.org/10.1080/13562517.2012.752728

Berson, Y., Halevy, N., Shamir, B., \& Erez, M. (2015). Leading from different psychological distances : A construallevel perspective on vision communication, goal setting, and follower motivation. The Leadership Quarterly, 26(2), 143-155. https://doi.org/10.1016/j.leaqua.2014.07.011

Bishop, K., \& International, S. A. (2002). New Roles, Skills and Capabilities for the Knowledge-focused Organisation: Standards Australia International.

Bodenheimer, T., \& Handley, M. A. (2009). Goal-setting for behavior change in primary care : An exploration and status report. Patient Education and Counseling, 76(2), 174-180. https:/ / doi.org/10.1016/j.pec.2009.06.001

Byrne, B. M. (2009). Structural Equation Modeling With AMOS: Basic Concepts, Applications, and Programming, Second Edition: Taylor \& Francis.

Cassuto, L. (2010). Advising the Struggling Dissertation Student. Chronicle of Higher Education, 57(11), A51-A53.

Catania, G. (2014). The unintended consequences of motivational techniques : Goal setting and unethical behavior in the Maltese financial services Industry. Procedia-Social and Behavioral Sciences, 109, 1375-1385. https:/ / doi.org/10.1016/j.sbspro.2013.12.640

Chatti, M. A. (2012). Knowledge management: a personal knowledge network perspective. Journal of Knowledge Management, 16(5), 829-844. https:/ / doi.org/10.1108/13673271211262835

Chen, K.-C., \& Jang, S.-J. (2010). Motivation in online learning : Testing a model of self-determination theory. Computers in Human Behavior, 26(4), 741-752. https:/ / doi.org/10.1016/j.chb.2010.01.011

Chin, W. W. (1998). The partial least squares approach for structural equation modeling Modern methods for business research (pp. 295-336). Mahwah, NJ, US: Lawrence Erlbaum Associates Publishers.

Cohen, J. (1988). Statistical Power Analysis for the Behavioral Sciences (2nd ed.). Hillsdale, UK: Lawrence Erlbaum Associates.

Debowski, S. (2007). Knowledge Management: Wiley India Pvt. Limited.

Fang, E., Evans, K. R., \& Zou, S. (2005). The moderating effect of goal-setting characteristics on the sales control systems-job performance relationship. Journal of Business Research, 58(9), 1214-1222. https:// doi.org/10.1016/j.jbusres.2004.03.006

Fornell, C., \& Larcker, D. F. (1981). Evaluating structural equation models with unobservable variables and measurement error. Journal of Marketing Research (JMR), 18(1), 39-50. https://doi.org/10.1177/002224378101800104

Fried, Y., \& Slowik, L. H. (2004). Enriching goal-setting theory with time: An integrated approach. Academy of Management Review, 29(3), 404-422. https://doi.org/10.5465/amr.2004.13670973

George, J. M., \& Jones, G. R. (2000). The role of time in theory and theory building. Journal of Management, 26(4), 657-684. https://doi.org/10.1177/014920630002600404

Grolnick, W. S. (2015). Mothers' motivation for involvement in their children's schooling : mechanisms and outcomes. Motivation and Emotion, 39(1), 63-73. https:/ / doi.org/10.1007/s11031-014-9423-4

Hagström, E., \& Lindberg, O. (2013). Three theses on teaching and learning in higher education. Teaching in Higher Education, 18(2), 119-128. https:/ / doi.org/10.1080/13562517.2012.694097

Hair, J. F. (2013). A Primer on Partial Least Squares Structural Equation Modeling (PLS-SEM): SAGE Publications.

Hair, J. F., Hult, G. T. M., Ringle, C., \& Sarstedt, M. (2014). A Primer on Partial Least Squares Structural Equation Modeling (PLS-SEM).

Hair, J. F., Ringle, C. M., \& Sarstedt, M. (2011). PLS-SEM: Indeed a silver bullet. Journal of Marketing Theory E Practice, 19(2), 139-152. https:/ / doi.org/10.2753/MTP1069-6679190202

Henseler, J., \& Sarstedt, M. (2013). Goodness-of-fit indices for partial least squares path modeling. Computational Statistics, 28(2), 565-580. https:/ / doi.org/10.1007/s00180-012-0317-1

Henseler, J., Dijkstra, T. K., Sarstedt, M., Ringle, C. M., Diamantopoulos, A., Straub, D. W., . . Calantone, R. J. (2014). Common Beliefs and Reality About PLS: Comments on Rönkkö and Evermann (2013). Organizational Research Methods, 17(2), 182-209. https:/ / doi.org/10.1177/1094428114526928

Henseler, J., Ringle, C., \& Sarstedt, M. (2015). A new criterion for assessing discriminant validity in variance-based structural equation modeling. Journal of the Academy of Marketing Science, 43(1), 115-135. https:/ / doi.org/10.1007/s11747-014-0403-8 
Hildreth, P. M., \& Kimble, C. (2004). Knowledge Networks: Innovation Through Communities of Practice: Idea Group Pub. https:/ / doi.org/10.4018/978-1-59140-200-8

Huang, T.-C., Jeng, Y.-L., Hsiao, K.-L., \& Tsai, B.-R. (2016). SNS collaborative learning design: enhancing critical thinking for human-computer interface design. Universal Access in the Information Society, 1-10. https:/ / doi.org/10.1007/s10209-016-0458-z

Hulland, J. (1999). Use of partial least squares (PLS) in strategic management research: a review of four recent studies. Strategic Management Journal, 20(2), 195-204. https://doi.org/10.1002/(SICI)10970266(199902)20:2<195::AID-SMJ13>3.0.CO;2-7

Hunt, C. (2001). Climbing Out of the Void: Moving from chaos to concepts in the presentation of a thesis. Teaching in Higher Education, 6(3), 351-367. https:// doi.org/10.1080/13562510120061214

Kimble, C., Hildreth, P. M., \& Bourdon, I. (2008). Communities of Practice: Creating Learning Environments for Educators: Information Age Pub.

Landers, R. N., Bauer, K. N., \& Callan, R. C. (2017). Gamification of task performance with leaderboards: A goal setting experiment. Computers in Human Behavior, 71, 508-515. https:/ / doi.org/10.1016/j.chb.2015.08.008

Latham, G. P., \& Locke, E. A. (1991). Self-regulation through goal setting. Organizational Behavior and Human Decision Processes, 50(2), 212-247. https:/ / doi.org/10.1016/0749-5978(91)90021-k

Lin, S., Hung, T.-C., \& Lee, C.-T. (2015). Revalidate forms of presence in training effectiveness: Mediating effect of self-efficacy. Journal of Educational Computing Research, 53(1), 32-54. https:/ / doi.org/10.1177/0735633115588772

Lindsay, S. (2015). What works for doctoral students in completing their thesis? Teaching in Higher Education, 20(2), 183-196. https:// doi.org/10.1080/13562517.2014.974025

Locke, E. A. (1968). Toward a theory of task motivation and incentives. Organizational Behavior and Human Performance, 3(2), 157-189. https:/ / doi.org/10.1016/0030-5073(68)90004-4

Locke, E. A., \& Latham, G. P. (1990). A Theory of Goal Setting $\mathcal{E}$ Task Performance: Prentice-Hall, Inc.

Locke, E. A., \& Latham, G. P. (2002). Building a practically useful theory of goal setting and task motivation : A $35-$ year odyssey. American Psychologist, 57(9), 705-717. https:/ / doi.org/10.1037/0003-066X.57.9.705

Locke, E. A., \& Latham, G. P. (2006). New directions in Goal-Setting Theory. Current Directions in Psychological Science, 15(5), 265-268. https:// doi.org/10.1111/j.1467-8721.2006.00449.x

Locke, E. A., \& Latham, G. P. (2015). Chapter Four - Breaking the Rules: A Historical Overview of Goal-Setting Theory. In J. E. Andrew (Ed.), Advances in Motivation Science (Vol. Volume 2, pp. 99-126): Elsevier. https:/ / doi.org/10.1016/bs.adms.2015.05.001

Locke, E. A., Cartledge, N., \& Knerr, C. S. (1970). Studies of the relationship between satisfaction, goal-setting, and performance. Organizational Behavior and Human Performance, 5(2), 135-158. https:/ /doi.org/10.1016/00305073(70)90011-5

O'Leary-Kelly, S. W., \& Vokurka, R., J. (1998). The empirical assessment of construct validity. Journal of Operations Management, 16(4), 387-405. https:/ / doi.org/10.1016/s0272-6963(98)00020-5

Roberts, C. M. (2004). The Dissertation Journey: A Practical and Comprehensive Guide to Planning, Writing, and Defending Your Dissertation: SAGE Publications.

Ryan, R. M., \& Deci, E. L. (2000). Intrinsic and extrinsic motivations: Classic definitions and new directions. Contemporary Educational Psychology, 25(1), 54-67. https:/ / doi.org/10.1006/ceps.1999.1020

Shea, P., \& Bidjerano, T. (2008). Measures of quality in online education: an investigation of the community of inquiry model and the net generation. Journal of Educational Computing Research, 39(4), 339-361. https:// doi.org/10.2190/EC.39.4.b

Sobel, M. E. (1982). Asymptotic confidence intervals for indirect effects in Structural Equation Models. Sociological Methodology, 13, 290-312. https:// doi.org/10.2307/270723

Sonnentag, S. (2012). Time in organizational research: Catching up on a long neglected topic in order to improve theory. Organizational Psychology Review, 2(4), 361-368. https:/ / doi.org/10.1177/2041386612442079

Stößlein, M., \& Kanet, J. J. (2016). Undergraduate research experiences: Identifying lessons learned and challenges for business schools. The International Journal of Management Education, 14(3), 349-367. https://doi.org/10.1016/j.ijme.2016.07.004

Thomas, R. M., \& Brubaker, D. L. (2000). Theses and Dissertations: A Guide to Planning, Research, and Writing: Bergin \& Garvey.

Vinzi, V. E. (2010). Handbook of Partial Least Squares: Concepts, Methods and Applications: Springer Berlin Heidelberg. 
Wenger, E., McDermott, R. A., \& Snyder, W. (2002). Cultivating Communities of Practice: A Guide to Managing Knowledge: Harvard Business Press.

Zhao, L., Lu, Y., Wang, B., \& Huang, W. (2011). What makes them happy and curious online? An empirical study on high school students' Internet use from a self-determination theory perspective. Computers $\mathcal{E}$ Education, 56(2), 346-356. https:/ / doi.org/10.1016/j.compedu.2010.08.006

APPENDIX

\section{Measurement Scale Items}

\begin{tabular}{|c|c|}
\hline Construct/ Scale & Items \\
\hline \multicolumn{2}{|l|}{ Goal-setting (GS) } \\
\hline GS1 & I set specific goals for thesis. \\
\hline GS2 & I invite my advisor to discuss each task objective of thesis writing. \\
\hline GS3 & Thesis writing is an attainable goal. \\
\hline \multicolumn{2}{|c|}{ Self-determination (SD) } \\
\hline SD1 & My advisor encourages me to think critically. \\
\hline SD2 & I derive enjoyment from thesis writing. \\
\hline SD3 & I achieve the objective of self-actualization. \\
\hline \multicolumn{2}{|l|}{ Self-efficacy (SE) } \\
\hline SE1 & I feel that I have advanced my interpersonal communication skills. \\
\hline SE2 & I feel that I have gained knowledge and/or skills related to future practice. \\
\hline SE3 & I feel that I have achieved the practical application of the course content I have learned. \\
\hline \multicolumn{2}{|c|}{ Community of practice (CoP) } \\
\hline CoP1 & When working on my thesis, I maintain a positive interaction with my peers. \\
\hline $\mathrm{CoP2}$ & When working on my thesis, my peers and I are mindful of our writing status. \\
\hline $\mathrm{CoP3}$ & When working on my thesis, my peers and I comment on each other's work. \\
\hline \multicolumn{2}{|c|}{ Knowledge ecology (KE) } \\
\hline KE1 & When working on my thesis, I perceive myself being part of a collaborative community. \\
\hline KE2 & We share writing know-how with each other. \\
\hline KE3 & I am motivated to write regularly and keep up with the schedule by interacting with others. \\
\hline \multicolumn{2}{|c|}{ Innoversity perception (IP) } \\
\hline IP1 & I can identify the knowledge or skills that I lack. \\
\hline IP2 & The variety of knowledge motivates me to generate innovation. \\
\hline IP3 & Interaction with others motivates me to come up with innovative thoughts. \\
\hline IP4 & My problem solving skills are enhanced. \\
\hline IP5 & The variety of knowledge enriches my writing. \\
\hline
\end{tabular}

\section{http://www.ejmste.com}

